\title{
Influence of geometric and dynamic parameters of a water-polymer jet on characteristics of food products hydro-cutting process
}

\section{Andriy Pogrebnyak ${ }^{1}$, Volodymyr Pogrebnyak ${ }^{2}$, Iryna Perkun², Nataliia Vasyliv ${ }^{2}$}

\author{
1 - University of Customs and Finance, Dnipro, Ukraine \\ 2 - National Technical University of Oil and Gas, Ivano-Frankivsk, Ukraine
}

\section{Keywords: \\ Cutting \\ Jet \\ Polyethylene \\ oxide \\ Nozzle}

Pressure

\section{Article history: \\ Received \\ 30.05.2019 \\ Received in revised \\ form 18.10.2019 \\ Accepted \\ 30.03.2020}

\section{Corresponding}

author:

Volodymyr

Pogrebnyak

E-mail:

vgpogrebnyak@

gmail.com

DOI:

$10.24263 / 2304-$

974X-2020-9-1-17

\section{Abstract}

Introduction. The process of water-polymer jet cutting of food products in order to increase the efficiency of the method of hydro-jet cutting by modifying the working fluid is investigated.

Materials and methods. The process of cutting chicken fillet, hake fish, beef and pork meat is researched. The experiments were carried out at temperatures of $-7{ }^{\circ} \mathrm{C}$ and $-25^{\circ} \mathrm{C}$, pressure changes from $50 \mathrm{MPa}$ to $150 \mathrm{MPa}$, nozzle diameter $0.35 \cdot 10^{-3}, 0.6 \cdot 10^{-3} \mathrm{~m}$ and velocity of the water-polymer jet movement relative to the sample of food product of $0.015,0.025,0.050$ and $0.100 \mathrm{~m} / \mathrm{s}$. The PEO concentration with molecular mass of $6 \cdot 10^{6}, 4 \cdot 10^{6}$ and $3 \cdot 10^{6}$ varied from 0 till $0.05 \%$.

Results and discussions. The depth of the cut in a frozen food product increases quite rapidly with the increasing of concentration and PEO molecular mass and reaches its maximum at some optimal concentrations $\left(\mathrm{C}_{\mathrm{opt}}\right)$. For PEO with a molecular mass of $3 \cdot 10^{6}$, the $\mathrm{C}_{\mathrm{opt}}$ equal to $0.015-0.020 \%$, and for molecular mass of $4 \cdot 10^{6}$ and $6 \cdot 10^{6}-$ $0.007-0.010 \%$ and $0.0015-0.0020 \%$, respectively. Increasing the diameter of the nozzle hole under the constant pressure of PEO water solution leads to increasing of the cutting depth in a food product. Noted character of influence of nozzle hole diameter of hydro-cutting jetshaping head on the cutting depth is due to the fact that the nozzles usage with a relatively big nozzle outlet diameter under the constant velocity of water-polymer jet movement in relation to the food sample and pressure of PEO water solution in front of the nozzle should lead to increasing of energy per unit of the cutting food product surface. To achieve the same cutting depth of frozen food products (in the range of -7 and $-25{ }^{\circ} \mathrm{C}$ ) it's enough to have water-polymer jet pressure of only $45-65 \%$ from the water jet, and vice versa, under the same initial pressure, 1.5-2.5 times increase in the depth and cutting velocity with water-polymer jet is observed, what tells about the special mechanism of its interaction with a food product. The dependence of the dimensionless cutting depth by water-polymer jet in frozen food products from the dimensionless distance to the nozzle section is obtained. The usage of high-velocity jet of PEO water solution for cutting frozen food products considerably increases the efficiency of the cutting process and the quality of the cutting surface.

Conclusions. In order to significantly improve the efficiency of food products water-cutting process, it is advisable to use jet of PEO water solution as the working fluid. 


\section{Introduction}

Scientific research in the field of cutting of different materials by high-speed water-jet $[1,2]$ show that the efficiency of the cutting process (depth of cut) is significantly increased under water pressures above $400 \mathrm{MPa}$. The results of research carried out in $[1,3]$ show that the destruction efficiency is nonlinear (depth of cut is increasing more intense than the hydraulic power supplied). In works $[4,5]$ is shown the results of the research of cutting process of thin polymeric materials by high-pressure water jets. It was found that with an increase of the nozzle diameter from $0.1 \cdot 10^{-3}$ till $0.4 \cdot 10^{-3} \mathrm{~m}$, the cutting depth in the material decreases. For example, for vinyl plastics in 2.85 times, for getinax in 5 times and for fiberglass in 8 times. It should be noted, that there is a critical pressure below which the destruction process does not occur, and temperature reduction of the food product to $-25{ }^{\circ} \mathrm{C}$ and below, makes impossible to use water-jet cutting under pressures less than $200-300 \mathrm{MPa}$ [6-8].

Cutting with using water-jet mixed with abrasive (sand, etc.) allows to cut virtually any material [9-11]. During contact with the material being cut, the kinetic energy of the waterjet with the abrasive is converted into mechanical energy of the material micro-destruction, and the cutting process takes place $[12,13]$. Obviously, the use of the traditional abrasive water-jet cutting method in the food industry is not possible at all, due to the inevitable contamination of the product with abrasive substances.

In hydro-jet cutting of food products, a high-velocity thin jet of fluid is used as the cutting unit $[6,7]$. The ability to obtain the necessary hydrodynamic characteristics of the hydro-jet, that providing maximum productivity depends on the properties of the working fluid. Minimization of energy costs, first of all, should be provided by reducing of the fluid working pressure before the nozzle to the lowest [7]. Therefore, the choice of type and content of the working fluid is one of the main issues that need to be addressed when developing the technological process of food products hydro-jet cutting. Solution this question can be approached using the observed features in the hydrodynamic behavior of polymer solutions under longitudinal flow [14-17]. Longitudinal Velocity Gradient is realized in the inlet section of the nozzle [18-20]. The polymer should be a safe substance and allowed for use in the food industry. Such polymer can be polyethylene oxide (PEO), which is a safe substance and used in the food industry as a thickener, flocculant, etc. [21, 22]. Patent No. 74609. 2012, Ukraine (Water-polymer Method of Cutting Frozen Food Products and Materials) indicates the perspective of cutting food products by water-polymer jet.

The aim of the work is to establish regularities of the influence of geometric and dynamic parameters of water-polymer jet on the frozen food products cutting efficiency needed for supporting of the design and processing works of the food products hydro-cutting equipment.

\section{Materials and methods}

Materials: chicken fillet, hake fish, beef [7,19] and pork meat, polyethylene oxide solutions of molecular mass $3 \cdot 10^{6}, 4 \cdot 10^{6}$ and $6 \cdot 10^{6}$ [20-22].

Experimental methods of study with the use age of: the created hydro-stand with a working pressure up to $500 \mathrm{MPa}$ and the possibility to change and control both integral and differential parameters of food products cutting process by water-polymer jet; developed 
special stands with temperature control and temperature stabilization within a wide range (up $+20^{\circ} \mathrm{C}$ to $-40^{\circ} \mathrm{C}$ ); capillary and rotary viscometers for rheological measurements $[7,20]$. The profilograms of the cutting surfaces in the food product were obtained by the stylus method of measurement. The profilograms obtained by this method allow not only to record the profile of the lateral cutting surface, but also to measure the parameters of roughness, waviness and deviation from the form. The quality of cutting surfaces in frozen food products was determined by using profilograph-profilometer block design with digital display of measurement results. This device allows to measure parameters of the roughness $R_{a}$ from 0.02 till $100 \mathrm{mkm}$ and $\mathrm{H}_{\max }$ and $\mathrm{H}_{\text {min }}$ from 0.1 till $1000 \mathrm{mkm}$. The device error does not exceed $10 \%$. The proposed three-grade scale for assessing the quality of the lateral cutting surface is given in the work [7].

\section{Results and discussion}

The criteria for assessing the efficiency of the food products cutting process by the water-polymer jet is the cutting depth $h$ and the growth rate of the lateral cutting surface $S_{0}$ $[7,20]$. The growth rate of the lateral surface characterizes the productivity of this process [7]. The productivity of the process of hydro-jet water-polymer food products cutting depends, firstly, on power and geometric properties of the high-speed water-polymer jet, the mutual arrangement of the water-polymer jet and food product, hardness, cutting marginal stress and tensile strength under uniaxial compression of food products, sizes of cutting food product, and also of the molecular mass of PEO and its concentration in the water-polymer jet [20].

First, let's consider the influence of PEO concentration, and then the geometric and dynamic parameters of the hydro-jet on the characteristics of the process of hydro-jet waterpolymer food products cutting with different subzero temperatures.

\section{Influence of PEO concentration and distance from the nozzle section to surface of food product on the process of hydro-jet water-polymer cutting}

Experimental studies of the influence of distance from the nozzle section to the frozen food product cutting surface $l_{0}$ on the cutting depth $\mathrm{h}$ were carried out on samples of beef and pork, and also of the hake fish and chicken fillet at temperatures $t$ from room temperature till $-25{ }^{\circ} \mathrm{C}$ and the pressure change $\Delta \mathrm{P}_{0}$ from $50 \mathrm{MPa}$ till $150 \mathrm{MPa}$, nozzle diameter $\mathrm{d}_{\text {noz. }}$ of $0.35 \cdot 10^{-3}, 0.6 \cdot 10^{-3} \mathrm{~m}$ and the speed of water-polymer jet movement relative to the food product sample $V_{\text {m.j. }}$ of $0.015,0.025,0.050$ and $0.100 \mathrm{~m} / \mathrm{s}$. The PEO concentration of molecular mass $\mathrm{M}_{\mathrm{PEO}}$ of $3 \cdot 10^{6}, 4 \cdot 10^{6}$ and $6 \cdot 10^{6}$ varied from 0 till $0.05 \%$. The distance from the nozzle to the food product cutting surface $l_{0}$ varied from $2 \cdot 10^{-3}$ to $100 \cdot 10^{-3} \mathrm{~m}$.

Figure 1 shows the dependence of the cutting depth in fillet of the hake fish, with a temperature of minus $25^{\circ} \mathrm{C}$ and the distance between its surface and the nozzle section under various $\mathrm{PEO}$ concentrations in water-polymer jet. 


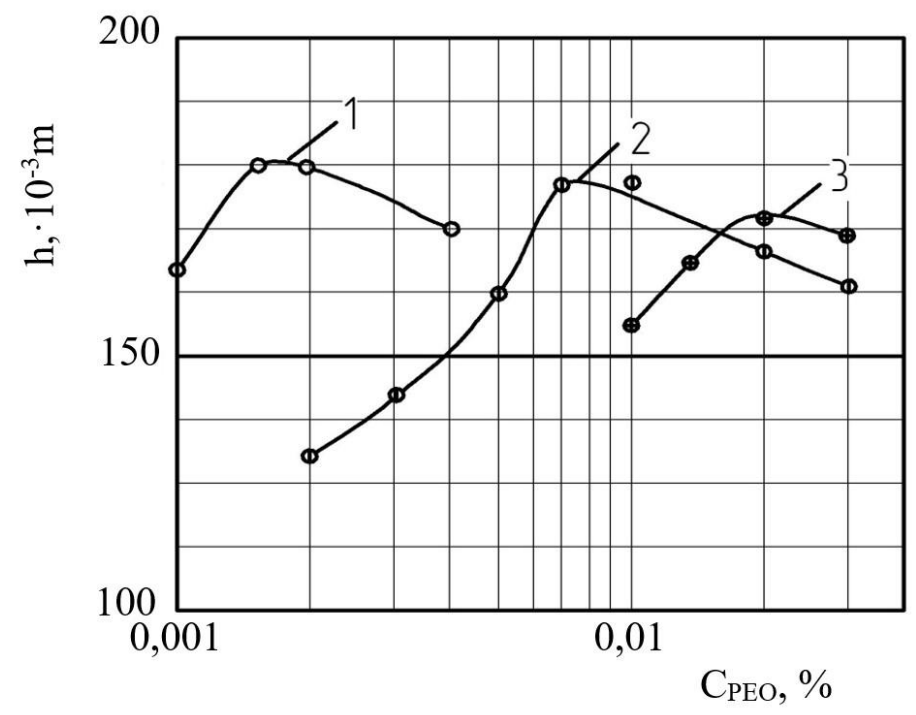

Figure 1. Dependence of the cutting depth in the fillet of hake fish on PEO concentration in water-polymer jet

$\left(\mathrm{t}=-25^{\circ} \mathrm{C}, \Delta \mathrm{P}_{0}=100 \mathrm{MPa}, \mathrm{d}_{\mathrm{noz} .}=0.6 \cdot 10^{-3} \mathrm{~m}, \mathrm{~V}_{\mathrm{m} . \mathrm{j} .}=25 \cdot 10^{-3} \mathrm{~m} / \mathrm{s}, \mathrm{l}_{0}=\mathrm{l}_{\mathrm{opt}}\right.$;

МРEO: $1-6 \cdot 10^{6}, 2-4 \cdot 10^{6}, 3-3 \cdot 10^{6}$ )

The provided material shows that the cutting depth in fillet of the hake fish increases quite greatly with increasing PEO concentration and molecular mass and reaches its maximum at some optimal concentrations. For PEO with a molecular mass of $3 \cdot 10^{6}$, the optimal concentration equals $0.015-0.020 \%$, and for molecular mass of $4 \cdot 10^{6}$ and $6 \cdot 10^{6}$ $0.007-0.010 \%$ and $0.0015-0.0020 \%$, respectively.

Data describing the influence of distance from the nozzle section to the food products surface, which are cutting by water-polymer jet, on the cutting depth, are given in Table 1 (for chicken fillet), in Figure 2 (for pork meat) and in Table 2 (for beef meat). The waterpolymer jet had the PEO concentration, which corresponds to the optimum.

The provided material shows that the dependence of the cutting depth $h$ on the distance between nozzle section and frozen food surface $l_{0}$ passes through the maximum. Such character of the dependence $h$ on $l_{0}$ is maintained under different experiment conditions, that is, for all researched by us pressures of water PEO solution $\Delta P_{0}$, nozzle diameters $d_{\text {noz. }}$. and speeds of water-polymer jet movement relative to the sample of the frozen food product $\mathrm{V}_{\mathrm{m} . \mathrm{j}}$. At relatively small distances from 0 to some $\mathrm{l}_{\mathrm{opt}}$ an increase in the cutting depth with increasing distance from the nozzle section to the frozen food product surface is probably due to the fact that the process of jet formation does not stopped immediately at the nozzle section, but at some distance from it, equal $l_{\text {opt. }}$. In this case, it should be noted that the distance $\mathrm{l}_{\mathrm{opt}}$ from this point of view is rational. 
Table 1

An influence of distance from the nozzle section to the chicken fillet surface, which is cut by the water-polymer jet, speed of jet movement and nozzle diameter on the cutting depth

$\left(\mathrm{CPEO}_{\mathrm{P}}=0,007 \%, \mathrm{MPEO}=\mathbf{4} \cdot 10^{6}, \Delta \mathrm{P}_{\mathbf{0}}=150 \mathrm{MPa}\right)$

\begin{tabular}{|c|c|c|c|c|c|c|c|c|c|c|c|c|}
\hline \multirow{3}{*}{ 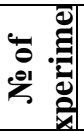 } & \multirow{3}{*}{ 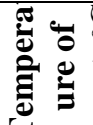 } & \multirow{3}{*}{$\begin{array}{c}\text { dnoz., } \\
10^{-3} \\
\text { m } \\
\end{array}$} & \multirow{3}{*}{$\begin{array}{l}V_{\mathrm{m} . \mathrm{j} .} \\
10^{-3} \\
\mathrm{~m} / \mathrm{s}\end{array}$} & \multicolumn{9}{|c|}{ Cutting depth $\mathrm{h}, 10^{-3} \mathrm{~m}$} \\
\hline & & & & \multicolumn{9}{|c|}{$\mathrm{lo}_{\mathrm{o}}, 10^{-3} \mathrm{~m}$} \\
\hline & & & & 2 & 2.5 & 3.5 & 4 & 6 & 10 & 20 & 60 & 90 \\
\hline 1 & \multirow{3}{*}{-7} & \multirow{2}{*}{0.35} & 50 & 110 & 117 & 133 & 135 & 141 & 188 & 136 & 126 & 122 \\
\hline 2 & & & 100 & 66 & 71 & 80 & 81 & 82 & 85 & 81 & 75 & 72 \\
\hline 4 & & 0.6 & 100 & 111 & 120 & 135 & 138 & 140 & 143 & 138 & 126 & 122 \\
\hline 5 & \multirow{5}{*}{-25} & \multirow{3}{*}{0.35} & 25 & 105 & 123 & 145 & 142 & 149 & 151 & 142 & 136 & 126 \\
\hline 6 & & & 50 & 63 & 74 & 83 & 84 & 89 & 89 & 84 & 75 & 72 \\
\hline 7 & & & 100 & 38 & 44 & 50 & 52 & 55 & 53 & 44 & 38 & 37 \\
\hline 8 & & \multirow{2}{*}{0.6} & 50 & 108 & 126 & 142 & 143 & 149 & 152 & 143 & 128 & 124 \\
\hline 9 & & & 100 & 65 & 74 & 84 & 87 & 92 & 92 & 75 & 62 & 56 \\
\hline
\end{tabular}

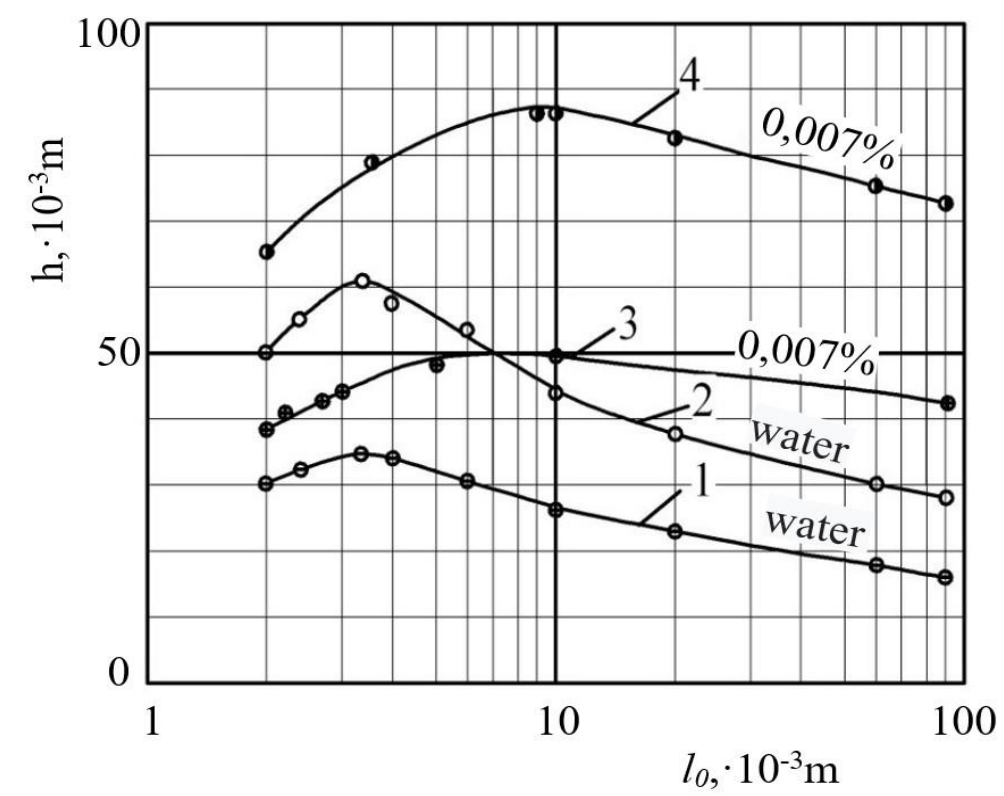

Figure 2. Dependence of the cutting depth by a water-polymer jet in the meat of pork on the distance between its surface and the nozzle section

$$
\begin{gathered}
\left(\mathrm{t}=-7^{\circ} \mathrm{C} ; \Delta \mathrm{P}_{\mathrm{o}}=100 \mathrm{MPa} ; \mathrm{d}_{\mathrm{noz}}=0.35 \cdot 10^{-3} \mathrm{~m} ; \mathrm{M}_{\mathrm{PEO}}=4 \cdot 10^{6} ;\right. \\
\left.\mathrm{V}_{\mathrm{m} . \mathrm{j} . \mathrm{i}} 1 \text { i } 3-100 \cdot 10^{-3} \mathrm{~m} / \mathrm{s}, 2 \text { i } 4-50 \cdot 10^{-3} \mathrm{~m} / \mathrm{s}\right)
\end{gathered}
$$


Table 2

Influence of the distance from the nozzle section to the beef meat surface, which is cut by the water-polymer jet, speed of jet movement and nozzle diameter on the cutting depth

$\left(\mathrm{C}_{\mathrm{PEO}}=\mathbf{0 , 0 0 7 \%}, \mathrm{M}_{\mathrm{PEO}}=\mathbf{4} \cdot \mathbf{1 0}^{6}, \Delta \mathrm{P}_{\mathbf{0}}=\mathbf{5 0} \mathrm{MPa}\right)$

\begin{tabular}{|c|c|c|c|c|c|c|c|c|c|c|c|c|}
\hline \multirow{3}{*}{ 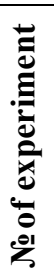 } & \multirow{3}{*}{$\begin{array}{c}\text { Temperature } \\
\text { of meat } \\
t,{ }^{\circ} \mathrm{C}\end{array}$} & \multirow{3}{*}{$\begin{array}{c}\mathrm{d}_{\text {noz. }} \\
10^{-3} \mathrm{~m}\end{array}$} & \multirow{3}{*}{$\begin{array}{l}V_{m . j .} \\
10^{-3} \\
\text { m/s }\end{array}$} & \multicolumn{9}{|c|}{ Cutting depth $\mathrm{h}, \mathbf{1 0}^{-3} \mathrm{~m}$} \\
\hline & & & & \multicolumn{9}{|c|}{$\mathrm{l}_{0}, 10^{-3} \mathrm{~m}$} \\
\hline & & & & 2 & 2.5 & 3.5 & 4 & 6 & 10 & 20 & 60 & 90 \\
\hline 1 & \multirow{6}{*}{$-7^{\circ} \mathrm{C}$} & \multirow{4}{*}{0.35} & 15 & 76 & 85 & 96 & 98 & 103 & 103 & 98 & 90 & 86 \\
\hline 2 & & & 25 & 51 & 58 & 65 & 67 & 70 & 71 & 68 & 61 & 59 \\
\hline 3 & & & 50 & 32 & 34 & 39 & 39 & 41 & 41 & 40 & 37 & 36 \\
\hline 4 & & & 100 & 19 & 20 & 23 & 23 & 24 & 24 & 23 & 22 & 21 \\
\hline 5 & & \multirow[b]{2}{*}{0.6} & 50 & 54 & 58 & 65 & 66 & 70 & 71 & 67 & 62 & 60 \\
\hline 6 & & & 100 & 32 & 35 & 39 & 40 & 40 & 41 & 40 & 37 & 36 \\
\hline 7 & \multirow{7}{*}{$-25^{\circ} \mathrm{C}$} & \multirow{4}{*}{0.35} & 15 & 50 & 58 & 66 & 68 & 71 & 72 & 68 & 62 & 59 \\
\hline 8 & & & 25 & 34 & 40 & 45 & 46 & 49 & 49 & 46 & 42 & 41 \\
\hline 9 & & & 50 & 21 & 24 & 27 & 27 & 29 & 29 & 27 & 25 & 24 \\
\hline 10 & & & 100 & 12 & 14 & 16 & 17 & 18 & 17 & 14 & 12 & 12 \\
\hline 11 & & \multirow{3}{*}{0.6} & 25 & 54 & 68 & 77 & 79 & 82 & 83 & 79 & 72 & 69 \\
\hline 12 & & & 50 & 35 & 41 & 46 & 47 & 49 & 50 & 47 & 42 & 40 \\
\hline 13 & & & 100 & 21 & 24 & 27 & 28 & 30 & 30 & 25 & 20 & 18 \\
\hline
\end{tabular}

Experimental results, which showing how changes the cutting depth by water-polymer jets in the frozen food products with the distance to the nozzle section is presented in Figure 3 . The gained experimental data are described by a function having a maximum in the area 15-20 of dimensionless distance from the nozzle.

Dependence of the $\mathrm{l}_{\text {opt. }}$ that corresponds to the maximum on the dependence curves $\mathrm{h} / \mathrm{h}_{\max }=\mathrm{f}\left(\mathrm{l}_{\mathrm{o}} / \mathrm{d}_{\text {noz. }}\right)$, on the nozzle diameter $\mathrm{d}_{\text {noz. }}$ and the length of the initial section $\mathrm{l}_{\text {i.p.w.j. }}$ of water-polymer jet with a variation coefficient of $10-15 \%$ in a dimensionless form has the following form:

$$
\frac{\mathrm{l}_{\text {opt. }}}{\mathrm{d}_{\text {noz. }}}=\frac{\dot{\varepsilon} \cdot \theta \cdot \mathrm{l}_{\text {i.p.w.j. }}}{5.4 \cdot \mathrm{d}_{\text {noz. }}}
$$

where $\dot{\varepsilon}$ - longitudinal velocity gradient in the entrance region of the nozzle, $\mathrm{s}^{-1} ; \theta-$ relaxation time of water PEO solution, $\mathrm{s}$.

When $\dot{\varepsilon} \theta<1$, the initial section of the water-polymer jet $l_{\text {i.w.p.j. }}$ is equal to the initial section of the water jet $l_{i . w . j .}$. This formula has the following usage limits: the water PEO solutions shall satisfy the Debay concentration criterion $-[\eta]_{0} \cdot C<1$ [23], and the value of the product of the longitudinal velocity gradient $\dot{\varepsilon}$ in the entrance region of the nozzle on the relaxation time $\theta$ of the water PEO solution, shall satisfy the condition $1 \leq \dot{\varepsilon} \theta<10$ [7]. 


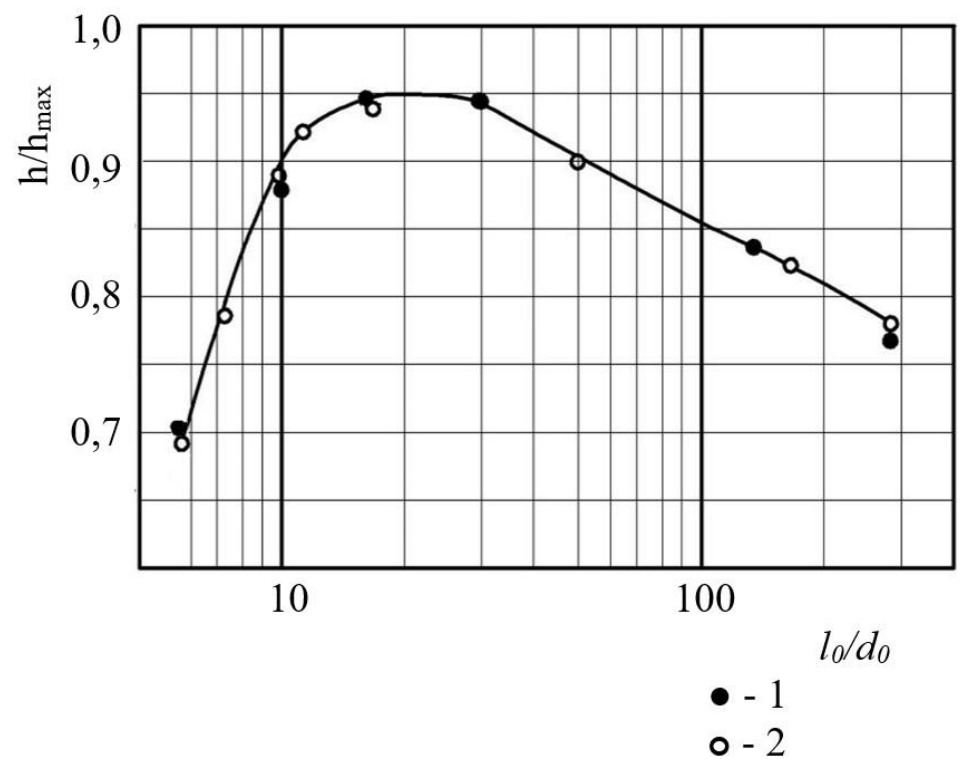

Figure 3. Dependence of the dimensionless cutting depth by a water-polymer jet in frozen food products on a dimensionless distance to the nozzle section: 1 - beef meat, 2 - fillet of hake fish

The increase in the distance $l_{0}$ more than the $l_{\text {opt. }}$ as a result of the interaction of the water-polymer jet with air, leads to a gradual loss of the kinetic energy of the jet, its diameter increases, and the value of the axial dynamic effect on the sample of the food product decreases, leading to a decrease the cutting depth. Having reached a certain limit value of the distance $\mathrm{l}_{\text {lim. }}$ from the nozzle section to the food product cutting surface, the cutting process is stopped.

\section{Influence of pressure and nozzle diameter on the process of hydro-jet water- polymer food product cutting}

The analysis of experimental data on the food products cutting by water-polymer jet, gained during the study of the influence of geometric and dynamic parameters of jets of water PEO solutions on the cutting depth in food products is shown (see Table 1 and 2, Figures 2 and 3), increases with increasing pressure of water PEO solution in front of the nozzle in the whole range of its values. This result is explained by the fact that an increase in the pressure of the water PEO solution in front of the nozzle leads to an increase in the hydraulic power of water-polymer jet, and, consequently, to increase its cutting ability.

The increase in diameter of nozzle hole under constant pressure of water PEO solution leads to an increase in the cutting depth in the food product. It is noted a character of influence of nozzle outlet diameter of hydro-cutting jet-shaping head on the cutting depth can be related to the fact, that the use of nozzles with a relatively large outlet diameter under a constant speed of water-polymer jet movement relative to the food product sample and pressure of water PEO solution in front of the nozzle, should lead to increase the amount of energy per 
unit of the food product cutting surface. A similar character of pressure influence $\Delta P_{0}$ and nozzle hole diameter $d_{n o z .}$ on the cutting depth $h$ has been observed also when cut samples of beef and pork meat at a temperature of liquid nitrogen $-195.8^{\circ} \mathrm{C}$ [7], as well as cutting of frozen minced fish, fillet of hake fish and chicken. However, in the works [4,5], there are other data indicating inverse relation between of the influence $d_{n o z}$. on the cutting depth, especially when thin polymeric materials cut by water jet. Thus, there is a reason to assert, that nowadays it is not fully found out the character of change of the cutting depth in the various materials from the nozzle hole diameter, even when cut by a water jet [7], and moreover - by water-polymer jet.

Considering the question on finding the rational nozzle outlet diameter of hydro-cutting jet-shaping head, it is also necessary to take into account that high-pressure water-polymer [7], as with water jets [6], of small diameter, are subject to faster decomposition and with $d_{\text {noz. }}<0.05 \cdot 10^{-3} \mathrm{~m}$ the process of hydro-cutting practically stops An increase of the nozzle diameter leads to increase of flow rate of water PEO solution, and, consequently, increases energy costs for the formation of a water-polymer jet.

At the same time, we gained the experimental data from the hydro-jet water-polymer frozen food products cutting, which is given above and the results of the water-cutting [6,7], convincingly show that the cutting depth of the relatively thick food products increases with the increase in the hydraulic parameters of water-polymer jets and increase nozzle outlet diameter of hydro-cutting jet-shaping head from $0.2 \cdot 10^{-3}$ till $0.8 \cdot 10^{-3} \mathrm{~m}$. These contradictions can be related to the structural and dynamic characteristics of high-speed water-polymer jet.

The gained experimental data also show the following: achievement of the same food products cutting depth (in the range from $-7^{\circ} \mathrm{C}$ to $-25^{\circ} \mathrm{C}$ ), enough the pressure of the waterpolymer jet is only $45-65 \%$ of the water jet, and vice versa, under the same initial pressure there is an increase in depth and cutting speed by water-polymer jet in 1.5-2.5 times, indicating a special mechanism of its interaction with the food product.

\section{Speed effect of high-speed water-polymer jet movement on the hydro-cutting process}

To determine the optimal conditions for the realization of the process of hydro-jet waterpolymer food products cutting that provide high productivity of the process [7, 20], the surface quality and shape of the cutting, it is necessary to establish the rational speed of waterpolymer jet movement relative to a food product that is cut, which depends on the parameters of the leak of the water-polymer jet from the nozzle, and provides the correct shape and high quality cuts.

Typical results of experimental studies of the process of hydro-jet water-polymer food products cutting are given on Figure 2, Tables 1 and 2. It is seen that the character of the change of dependence of the cutting depth in pork meat, fillet of broiler chicken and beef meat $\mathrm{h}$ from the speed of jet movement of water PEO solution $V_{m, j}$, relative to food samples, is qualitatively the same under different temperatures. An increase in the speed of the waterpolymer jet movement $V_{m . j}$. for water pressure of 50-150 MPa in front of the nozzle leads to a decrease in the cutting depth in the food product. The decrease in $h$ with increase in $V_{m . j}$, can be explained by the fact that under low speeds of the water-polymer jet movement, the density of energy spreading of the jet per unit of the cutting length is large. As a result, a greater cutting depth is formed in the food product than at high speeds of movement. For 
large $V_{m . j}$, the density of energy spreading of the water-polymer jet decreases, and thus, decreases the cutting depth.

It is worth noting that the decrease in the food product temperature, that is, an increase in the tensile strength for uniaxial compression, in other conditions is equal, take place corresponding decrease in the food product cutting depth [7]. This is due to the fact, that the cutting of stronger food products samples requires higher specific energy consumption.

Table 3 shows the width of cuts $b$ by high-speed jet of water PEO solution in frozen beef depending on the distance between the nozzle section and the food product surface for different water pressures and nozzle outlet diameters. The gained experimental data show that with the increase in the distance between the nozzle and the food product surface, the cutting width varies. It is seen that with increasing of nozzle diameter and distance between nozzle and food product surface, the cutting width $b$ increases. The dependence of the cutting width on the distance between the nozzle cut and the food product surface, that corresponds to the data given in Table 3, with reasonable accuracy, coincides with the dependence, which describes the change in the diameter of the water-polymer jet from the distance to the nozzle section. Experimental results given in Table 3 show that the cutting width $b b$ in the investigated range $l_{0}$ practically does not depend on the pressure of the water PEO solution in front of the nozzle $\Delta \mathrm{P}_{0}$.

Table 3

Cutting width during hydro-jet water-polymer cutting of frozen beef meat, depending on the distance between the nozzle section and the cutting surface

\begin{tabular}{|c|c|c|c|c|c|c|c|c|c|}
\hline \multirow{3}{*}{$\begin{array}{c}\text { № of } \\
\text { experiment }\end{array}$} & \multirow{3}{*}{$\begin{array}{c}\text { Temperature } \\
\text { of meat } \\
\text { t, }{ }^{\circ} \mathrm{C}\end{array}$} & \multirow{3}{*}{$\begin{array}{l}\Delta \mathbf{P}_{\mathbf{0}} \\
\mathbf{M P a}\end{array}$} & \multirow{3}{*}{$\begin{array}{c}d_{\text {noz. }}, \\
10^{-3} \\
\text { m }\end{array}$} & \multirow{3}{*}{$\begin{array}{l}V_{m . j}, \\
10^{-3} \\
\mathrm{~m} / \mathrm{s}\end{array}$} & \multicolumn{5}{|c|}{ Cutting width $b, 10^{3} \mathrm{~m}$} \\
\hline & & & & & \multicolumn{5}{|c|}{$\mathrm{l}_{0} \cdot 10^{3}, \mathrm{~m}$} \\
\hline & & & & & 5 & 10 & 20 & 50 & 90 \\
\hline 1 & \multirow{3}{*}{-7} & 100 & \multirow{3}{*}{0.35} & 15 & 0.35 & 0.36 & 0.37 & 0.40 & 0.47 \\
\hline 2 & & 100 & & 25 & 0.36 & 0.37 & 0.38 & 0.42 & 0.48 \\
\hline 3 & & 50 & & 15 & 0.35 & 0.36 & 0.37 & 0.41 & 0.48 \\
\hline 4 & \multirow{4}{*}{-25} & \multirow{2}{*}{100} & \multirow{2}{*}{0.35} & 15 & 0.36 & 0.37 & 0.37 & 0.42 & 0.47 \\
\hline 5 & & & & 25 & 0.36 & 0.37 & 0.38 & 0.42 & 0.47 \\
\hline 6 & & 100 & 0.60 & 15 & 0.61 & 0.63 & 0.65 & 0.71 & 0.80 \\
\hline 7 & & 50 & 0.60 & 15 & 0.61 & 0.65 & 0.67 & 0.73 & 0.84 \\
\hline
\end{tabular}

Experimentally confirmed independence or very weak dependence of the width $b$ on the pressure $\Delta P_{0}$ and speed of the water-polymer jet movement relative to the food product sample $V_{m . j .}$, may indicate a self-similar mode of leakage of water PEO solution from the nozzle.

For food products there are no objective methods for assessing the quality of lateral surfaces of cuts. In our experiments, the estimation of the quality of the lateral surfaces of the cuts during the hydro-jet water-polymer food products cutting was made visually, as well as using the profilograph-profilometer. It was established experimentally that the quality of cutting surface (in accordance to the evaluation criteria [7]) in the frozen food products 
improves with the increasing in speed of the water-polymer jet, cutting speed up to the rational value $V_{\text {rat.m.j. }}$, and, deteriorates with increasing in the nozzle diameter. A forming cut in the process of water-polymer frozen food products cutting under a very low cutting speed $\left(V_{m . j .}<<V_{\text {rat.m.j. }}\right)$ has the profile of A-shaped form, whereas under a high cutting speed ( $V_{m . j .}>V_{\text {rat.m.j. }}$ ) the profile of the cut has a weakly pronounced $\mathrm{V}$-shaped form. Cutting food products by a water-polymer jet under a speed close to its rational value leads to the formation of a cut of the П-shaped form.

When increasing distance between the nozzle and the surface of food product sample, which is cut, cutting width increasing due to the widening of the water-polymer jet, thus, the contact area of the jet with the food product also increasing, what is, in addition to other constant parameters of the water-polymer jet leak, reduce specific cutting pressure and increase the food product volume, which is removed per time unit, thus reducing productivity of the process of hydro-jet water-polymer cutting.

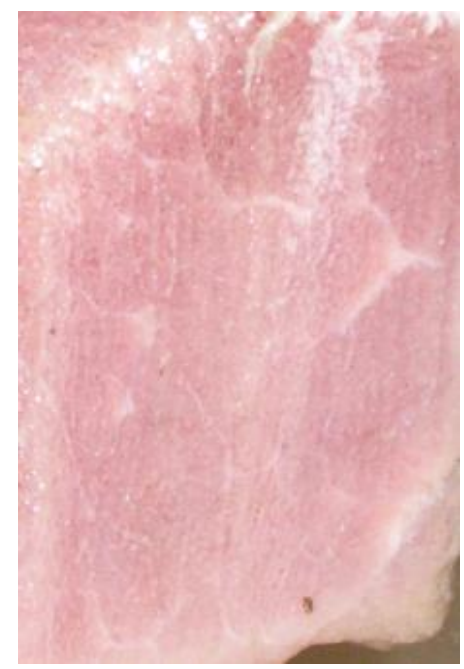

$a$

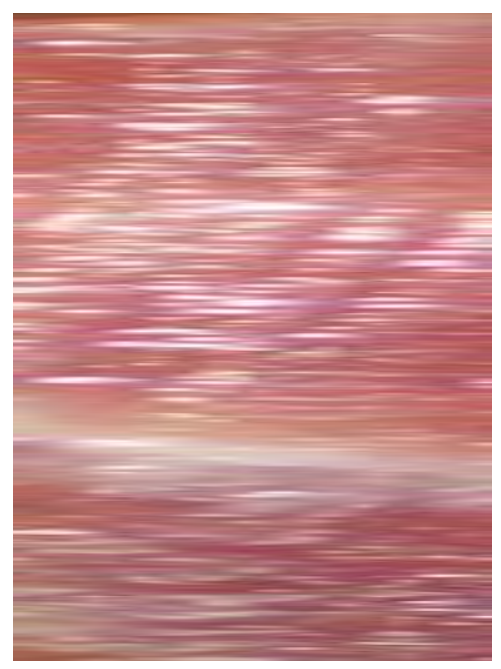

$b$

Figure 4. Photos of the cutting surfaces by the hydro-jets in a frozen pork meat: $a$ - the water-polymer jet, $b$ - the water jet

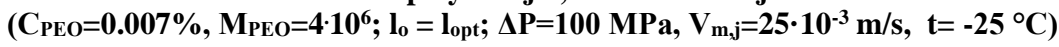

The Figure 4 shows the pictures of cutting surfaces in frozen pork meat related to "highquality" cutting (a) and "equel-quality" cutting (b). Experimental data show, that the quality of the frozen food product cutting surfaces when it is cut by a water-polymer jet is significantly higher than when it is cut by a water-jet. 


\section{Conclusions}

1. It was determined that the cutting depth in the food product increases quite greatly with increasing PEO concentration and molecular mass and reaches its maximum at some optimal concentrations. For PEO with a molecular mass of $3 \cdot 10^{6}$, the optimal concentration equal to $0.015-0.020 \%$, and for molecular mass of $4 \cdot 10^{6}$ and $6 \cdot 10^{6}$ $0.007-0.010 \%$ and $0.0015-0.0020 \%$, respectively.

2. It has been found that the intensification of the frozen food products water-cutting process due to the PEO impurity in the water-jet allows to reduce the rational working pressure in 3-4 times, that allows to considerably reduce the cost of the water-cutting equipment.

3. It is experimentally proved that the quality of surfaces of cuts in food products improves with the increasing speed of the water-polymer jet, cutting speed up to the rational value and gets worse with increasing of the nozzle diameter.

4. The interpretation of the experimental data, gained from the influence of water-jet polymeric impurities concentration in water jet, geometric and dynamic parameters of water-jet on the characteristics of the food products water-cutting process, requires study of structural changes occurring in the water-polymer jet under different modes of its leak from a nozzle, as well, as the degree of force of the water-polymer jet on barrier.

\section{References}

1. Hashish M., Steele D., Bothell D. (1997), Machining with Superpressure Water-jet, Int. J. of Machine tools Manufacturing, 37(4), pp. 465-479.

2. Hashish M. (1999), Cutting and drilling at 690MPa, Proceedings of the 10th American Water-jet Conference, Houston, pp. 137-152.

3. Wang J. (1999), Water-jet Machining of Polymer Matrix Composites - Cutting Performance, Erosive Process and Predictive Models. Int. J. of Advanced Manufacturing Technology, 15(10), pp. 757-768.

4. Hyung-Mok K., Chung-In, Wan-Mo K., Byung-Hee C. (1999), Rock cutting with water-jet and quantified roughness at cut wall. Proceeding of international symposium on New application of water Jet., Ishinomaki, Japan, pp. 373-383.

5. Tikhomirov R. A. (1992), Gidravlicheskaia rezka listovykh plastikov, Plasticheskie massy, 2, pp. 43-45.

6. Zapletnikov I. N., Gordienko A. V. (2012), Oborudovanie gidrorezaniia pishchevykh produktov, DonNUET, Donetsk.

7. Zapletnikov I. M., Poperechnyi A. M., Yeromenko D .O., Gordienko A.V. (2013), Innovatsiini pidkhody do polipshennia ekspluatatsiinykh kharakterystyk obladnannia kharchovykh vyrobnytstv, Knowledge, Donetsk.

8. Duspara M., Starcevic V., Samardzic I. (2018), Preliminary communication Analysis of Zones Created with Water-jet Cutting of AISI 316 L Corrosion Resistant Steel, Technical Gazette, 25, pp. 2616-621.

9. Selvan M. (2012), Effects of process parameters on surface roughness in abrasive waterjet cutting of aluminium, Frontiers of Mechanical Engineering, 7, pp. 439-444. 
10. Summers D. A. (1995), Water-jetting Technology, Printed in Great Britain by the Alden Press, Oxford, pp. 882-891.

11. Gyliene V. (2014), Investigation of abrasive waterjet cutting parameters influence on 6082 alluminium alloy surface roughness, Mechanika, 20(6), pp. 602-606.

12. Monkova K., Monka P., Cep R., Mullerova J., et al. (2011), Factor analysis of abrasive water-jet factors affecting the surface roughness of titanium, Technical Gazzete, 18(1), pp. 73-77.

13. Alsoufi A.M. (2007). Influence of Abrasive Water-jet Machining Parameters on the Surface Texture Quality of Carrara Marble, J. of Surface Engineered Materials and Advanced Technology, 7, pp. 25-37.

14. Ivanyuta Yu.F., (1986), Viscosity and diagrams of polyethylenoxide solution states, Izvestiya vysshikh uchebnykh zavedenii, khimiya s khimicheskaya tekhnologiya, 29(1), pp. 93-96.

15. Pogrebnyak A., Chudyk I., Pogrebnyak V., Perkun I. (2019), Coil-Uncoiled Chain Transition of Polyethylene Oxide Solutions under Convergent Flow, Chem. and Chem. Technology. 13(4), pp. 465-470.

16. Dyakonova N., Brestkin Yu., Agranova S., Tverdokhleb S. et al., (1989), Birefringence effects of polymer-solutions in hydrodynamic fields, Vysokomol. Soyed., B, 31(11), pp. 844-846.

17. Voloshin V.S., Naumchuka N.V. (2005), Nonstationary flow of solutions of flexiblechain polymers in a porous medium, J. Eng. Phys. and Thermophysics, 78(5), pp. 963968.

18. Pogrebnyak V.G., Ivanyuta Yu.F., Frenkel S.Ya. (1992), Structure of the hydrodynamic field and strain behavior of flexible macromolecules in convergent flow, Vysokomolekul. Soedin., A, 34(3), pp. 133-138.

19. Pogrebnyak A., Pogrebnyak V. (2017), Mechanism of the High Efficiency of the Cutting Frozen Food Products Using Water-jet with Polymer Additions, J. of food science and technology-Ukraine, 11(2), pp. 73-78.

20. Pogrebnyak A.V., Perkun I.V., Pogrebnyak V.G. (2017), Degradation of Polymer Solutions in a Hydrodynamic Field with a Longitudinal Velocity Gradient, J. Eng. Phys. and Thermophysics, 90(5), pp. 1219-1224.

21. Stone F.W., Stratta J.J. (1997), Ethylene oxide polymers, Encylopedia of polymer science and technology, New York, 6, pp. 103-145.

22. Salyanov V.I., Skuridin S.G., Toryanik A.I., Yevdokimov Yu.M., et al., (1978), Relation between molecular-structure of aqueous-solutio of polyethyleneoxide and compaction of double-stranded DNA-volecules, Molecular Biology, 12(3), pp. 367375.

23. Frenkel S.Ya., Eliashevich G.K., Panov Iu.N. (2007), Kontsentrirovannye rastvory polimerov (Termodinamika i struktura), Uspekhi khimii i fiziki polimerov, Moskow, Khimya, pp. 87-138. 